\title{
PARA ALÉM DA MORAL DO MACHO: A DIGNIDADE SEXUAL NO CÓGIDO PENAL BRASILEIRO
}

Sávio Silva de Almeida ${ }^{1}$

Resumo: O presente trabalho possui os direitos humanos como tema, tendo a dignidade sexual como enfoque. Sendo assim, o artigo tem como objetivo analisar a proteção da dignidade sexual no direito penal brasileiro. Trata-se assim de uma pesquisa qualitativa, de natureza descritiva, baseada em extensa revisão bibliográfica. Entende-se que a dignidade sexual decorre do princípio da dignidade humana, ou seja, não há dignidade humana se a dignidade sexual é violada. O processo de reconhecimento dos direitos humanos das mulheres foi fruto de um longo processo de participação ativa das mulheres na política mundial, que culminou com a inclusão dos debates de gênero no âmbito da justiça. Pois, percebeu-se que concorre para a violação da dignidade sexual a formação de uma sexualidade e subjetividade agressivas, quando a sexualidade poderia ser, ao contrário, vivenciada como um ato amoroso. Neste sentido, o direito penal sexual brasileiro, com base na Lei $n$. 12.015, tem caminhado no sentido de abandonar uma moral patriarcal, que hierarquiza as mulheres em "virgens", "honestas", "prostitutas" e "meretrizes", para promover e proteger a dignidade sexual das mulheres.

Palavras-chave: Dignidade Humana; Direitos Humanos; Sexualidade; Subjetividade; Patriarcado.

Abstract: This work has human rights as object, having sexual dignity as the focus. The article aims to analyze the protection of sexual dignity in the Brazilian criminal law. It is a descriptive qualitative research, based on an extensive literature review. It is understood that sexual dignity derives from the principle of human dignity, that is, there is no human dignity if sexual dignity is violated. The process of recognition of women's human rights was the result of a long process of active participation of women in world politics,

\footnotetext{
${ }^{1}$ Doutorando em Desenvolvimento Urbano - MDU/UFPE. Mestre em Desenvolvimento e Meio Ambiente PRODEMA/UFPE. Bacharel em Administração - FOCCA
} 


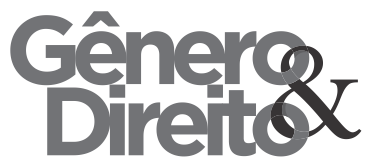

which led to the inclusion of gender debates in the field of justice. For it has been perceived that the formation of an aggressive sexuality and subjectivity competes for the violation of the sexual dignity, when sexuality could be experienced as a loving act. In this sense, the Brazilian sexual criminal law, based on Law 12,015, has been moving towards promoting and protecting the sexual dignity of women, by abandoning a patriarchal morality, which hierarchizes women as "virgins", "honest", "prostitutes" and "sluts".

Keywords: Human Dignity; Human rights; Sexuality; Subjectivity; Patriarchate.

\section{INTRODUÇÃO}

$\mathrm{O}$ presente artigo aborda a problemática acerca dos direitos humanos - sexuais -, tendo a dignidade sexual como enfoque. Neste sentido, são apresentadas, no presente trabalho, as ideias da dignidade humana, dos direitos humanos, da sexualidade e da subjetividade como dimensões importantes da dignidade sexual humana.
Cenco do Núcleo de Estudos e Pesquisas sobre Gênero e Direito Centro de Ciências Jurídicas - Universidade Federal da Paraíba V. 6 - $\mathrm{N}^{\circ} 02$ - Ano 2017

196

No capítulo 1, Dignidade Humana como Núcleo dos Direitos Humanos, a dignidade humana é apresentada como o fundamento dos direitos humanos, reconhecendo que não há dignidade humana, se não há dignidade sexual.

No capítulo 2, Direitos das Mulheres: Exclusão, Universalismo e Inclusão, são apresentadas três fases distintas dos direitos humanos com relação ao reconhecimento dos direitos das mulheres. Uma primeira fase em que os direitos humanos são direitos dos homens, representada pela Declaração dos Direitos do Homem e do Cidadão, de 1789. A segunda fase marcada pela universalização dos direitos humanos, representada pela Declaração Universal dos Direitos Humanos, de 1948. E a terceira fase marcada pela especificação da mulher como sujeito de direito, representada pela Convenção sobre a Eliminação de todas as Formas de Discriminação contra a Mulher, de 1979.

No capítulo 3, A Sexualidade e a Subjetividade Agressiva, é discutido como estigmas, preconceitos e desigualdades contribuem para a formação da sexualidade e da subjetividade agressiva. 


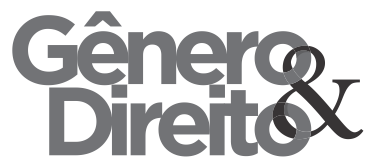

No capítulo 4, A Dignidade Sexual

no Direito Penal Brasileiro: Uma Abordagem Histórica, é demonstrado como o direito penal sexual brasileiro substituiu uma abordagem baseada numa moral patriarcal, que hierarquiza e inferioriza as mulheres, por uma abordagem que visa a promoção da igualdade, ou seja, que visa a promoção e a proteção da dignidade sexual das mulheres.

O trabalho conclui, portanto, que o Código Penal Brasileiro está caminhando para ir além da moral do macho humano, que hierarquiza as mulheres de acordo os seus interesses, para proteger a dignidade sexual, como bem jurídico intimamente ligado à dignidade humana, núcleo a ser protegido por todos os direitos humanos.

Trata-se de uma pesquisa qualitativa, descritiva e que se baseou em extensa revisão bibliográfica. $\mathrm{O}$ artigo tem como objetivo analisar a proteção da dignidade sexual no direito penal brasileiro.

\section{DIGNIDADE HUMANA COMO NÚCLEO DOS DIREITOS HUMANOS}

Cendico do Núcleo de Estudos e Pesquisas sobre Gênero e Direito Centro de Ciências Jurídicas - Universidade Federal da Paraíba V. 6 - No 02 - Ano 2017

197

A dignidade sexual decorre da dignidade humana, ou seja, a dignidade humana é violada sempre que a dignidade sexual é violada. Não há direitos humanos, se não há dignidade sexual. E sendo a dignidade humana o núcleo essencial de todos os direitos, faz-se necessário compreender o que é a dignidade humana para que se compreenda a dignidade sexual.

Atualmente, a doutrina majoritária reconhece que a vigência dos direitos humanos independe de sua declaração em tratados internacionais, constituições e leis, uma vez que se está diante de exigências de respeito à dignidade humana, que são exercidas contra todos os poderes estabelecidos, oficiais ou não (COMPARATO, 2013). O fundamento para a vigência dos direitos humanos, em última instância, é a convicção de que a dignidade da condição humana exige o respeito a certos bens ou valores, em quaisquer circunstâncias, ainda que tais bens e valores não sejam reconhecidos no ordenamento estatal, ou nos documentos normativos internacionais (COMPARATO, 2010).

Aconteceu com a dignidade humana algo semelhante ao que aconteceu 
na segunda metade século XX com os direitos humanos. No começo, eles se referiam ao homem em abstrato, ente genérico, independentemente de qualquer determinação concreta - cor, língua, sexo etc. -, reservando a cada ser humano o direito de ser tratado como qualquer outro. Em seguida, passou-se a considerar o homem concretamente na especificidade de seus diversos status, diferenciados de acordo com a idade, o sexo, as condições sociais ou físicas. O primeiro processo insiste na necessidade de tratamento igual dos seres humanos. O segundo processo insiste sobre a necessidade de se criar um tratamento diferenciado: a criança diversamente do adulto, o adulto do velho, a mulher do homem, o são do doente, e assim por diante, com diferenciações cada vez mais específicas (BECCHI, 2013).

São atributos da dignidade humana, os seguintes: a) respeito à autonomia da vontade, b) não coisificação do ser humano, c) garantia do mínimo existencial e d) respeito à integridade física e moral. Esses atributos estão ligados pela noção básica de respeito ao outro, que sintetiza todo o conteúdo do princípio da dignidade da pessoa humana. Esse respeito ao outro independe de quem seja o outro, pois pode ser qualquer pessoa.

Assim, a dignidade não é privilégio de alguns indivíduos escolhidos por razões culturais, econômicas ou étnicas, mas um atributo de todo ser humano, simplesmente pelo fato de ser humano (MARMELSTEIN, 2011).

De acordo com Soares (2010, p. 142):

Partindo da etimologia do vocábulo "dignidade", verifica-se que o termo está associado ao latim dignitas, que significa "valor intrínseco", "prestígio", "mérito" ou "nobreza". Daí provém o entendimento de que o ser humano é um fim em si mesmo, dotado de uma qualidade intrínseca que o torna insuscetível de converter-se em meio ou instrumento para a realização de interesses econômicos políticos e ideológicos.

[...]

Sendo assim, a dignidade da pessoa humana identifica um núcleo de integridade física e moral a ser assegurado a todas as pessoas por sua existência no mundo, relacionando-se tanto com a satisfação espiritual quanto com as condições materiais de subsistência do ser humano, vedando-se qualquer tentativa de degradação ou coisificação do ser humano em sociedade.

Esta compreensão da dignidade humana é muito recente, e, infelizmente, não é compartilhada ainda por todos os seres humanos. Há quem não se sinta incomodado com o sofrimento alheio, com a fome, com o racismo, com o sexismo, 


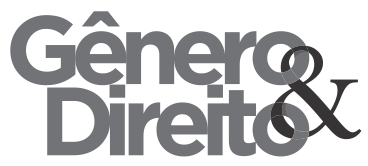

com a crescente desigualdade socioeconômica e política, com o déficit de moradia e saneamento, com o desemprego, com as guerras etc., enfim, com a materialização da exploração e da opressão.

Durantes milhares de anos, o Outro sempre foi o inimigo por antecipação, a ameaça a ser neutralizada ou da qual se deveria escapar. O Outro/Diferente deveria ser cuidadosamente evitado ou abatido. A hostilidade se multiplicou por incontáveis esferas. O Outro tinha crenças ininteligíveis, hábitos esdrúxulos, costumes exóticos e usava uma linguagem incompreensível. Desta maneira, teria uma origem diferente daquela do povo que o avaliava e não disporia de um estatuto que o pudesse considerar igual. Era passível de tratamento violento ou cruel, de ser destituído de seus títulos, família e posses, ser submetido a condições infames de vida, por ser distinto. Esse é o resumo da racionalização que justifica os preconceitos que sustentaram as discriminações e as ações hostis de uns povos contra outros, conduzindo ao apartheid, às limpezas étnicas através de confinamentos, genocídios e a criação de barreiras à imigração, bem como ao
Cico do Núcleo de Estudos e Pesquisas sobre Gênero e Direito Centro de Ciências Jurídicas - Universidade Federal da Paraíba V. 6 - No 02 - Ano 2017

199

escravismo. Tendo como elemento comum a visão de inferioridade, de uma condição subumana do Outro (KEINERT, 2012).

Pessoas de várias classes e estamentos, cientistas etc. foram queimados nas fogueiras, em nome do bem maior. Em prol da existência de uma religião única, mortes e torturas foram praticadas. Em nome da cor da pele ou de quaisquer outros motivos: mais atrocidades. Desta maneira, para definir a dignidade é preciso levar em conta todas as violações que foram praticadas, para lutar contra elas (NUNES, 2010).

O capitalismo histórico desenvolveu uma estrutura ideológica de humilhação opressiva - que conhecemos por racismo e sexismo - nunca vista antes. No capitalismo histórico o racismo é mais do que a xenofobia generalizada, e o sexismo é mais do que uma posição dominante do homem sobre a mulher. $\mathrm{O}$ sexismo, por exemplo, relega a mulher ao reino do trabalho não produtivo, duplamente humilhante, visto que a sua carga de trabalho aumentou e o trabalho produtivo se tornou, pela primeira vez na história, sob a economia mundial capitalista, a base da legitimação do 


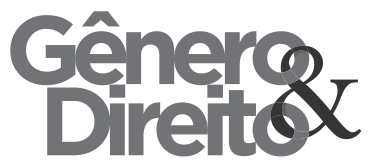

privilégio. Isso estabeleceu uma submissão dupla, que se demonstrou intratável dentro do sistema (WALLERSTEIN, 2001).

Desde as últimas décadas do século XIX, diversos movimentos de mulheres haviam se organizado nos EUA e na Europa para lutar por seus direitos, embora cindidos desde o início em duas grandes vertentes. As mulheres liberais das classes média e alta, de um lado, conhecidas como "sufragistas", que se limitavam a reivindicar o direito de voto feminino, sem deixar às vezes claro se sua reivindicação se referia ao sufrágio universal ou se toleravam a permanência das restrições a esse direito, baseadas na renda, na escolaridade e no patrimônio. Por outro lado, o movimento das mulheres socialistas, predominantemente proletárias, exigia o direito ao voto universal para todas as mulheres e homens que chegassem à maioridade, sem quaisquer restrições de natureza censitária, além de denunciar a dupla opressão, decorrente da dupla jornada de trabalho (no lar e na fábrica), a que as mulheres trabalhadoras estavam submetidas. Desta maneira, além do sufrágio universal, o movimento das socialistas lutava por dico do Núcleo de Estudos e Pesquisas sobre Gênero e Direito Centro de Ciências Jurídicas - Universidade Federal da Paraíba V. 6 - $\mathrm{N}^{\circ} 02$ - Ano 2017

bandeiras sociais, tais como aumentos de salários para todos, igualdade salarial com os homens, licença-maternidade, creches para os filhos das trabalhadoras, igualdade de direitos no casamento, direito de divórcio, assistência pública e gratuita à saúde, escolas públicas gratuitas, refeitórios e lavanderias populares etc. propostas conectadas ao programa de transformação socialista de seus países (TRINDADE, 2011).

Existe a possibilidade de construir a participação da mulher na produção, porém, tal produção está por ser construída. As mulheres entram no mercado de trabalho como um ser dependente, uma "extensão orgânica" de alguém. Quando a participação da mulher se tornou viável e necessária, tal participação se tornou uma força de trabalho socialmente estigmatizada. A demanda por equidade no trabalho deve ser acompanhada pela luta por creches, maternidades, abortos e todo um complexo de soluções para as necessidades das mulheres; sem tal tratamento especial a "equidade" tende a caminhar no sentido da sua própria negação. As mulheres devem combater as estruturas institucionais que perpetuam socialmente sua condição de 
inferioridade. Porém, há de se ressaltar, que as mulheres negras têm contribuído, em demasia, na luta contra o racismo e a opressão nacional, desde a escravidão até o presente. As mulheres devem lutar contra o sexismo, que permeia todo o aparato produtivo, e que as propõe possuir uma autoimagem de extensão da natureza humana desprovida de "masculinidade" (DAVIS, 2000).

De acordo com Mies (1993a) a ciência moderna e os "dispositivos mecânicos" não seriam desenvolvimentos possíveis sem a aplicação dos mesmos princípios de exploração e subordinação contra as colônias e as sua populações. As populações da África, da Ásia e da América foram tratadas tal como a natureza e a mulher na Europa: como "selvagens". Sem a riqueza que fora roubada das colônias, nem a moderna ciência nem o capitalismo europeus se teriam erguido entre os séculos XVII e XIX. A violência e a força constituem o fundamento invisível sobre o qual é edificada a ciência moderna. Daí a violência contra a natureza, entendida como mulher, e a violência contra a mulher nos seus pogroms às bruxas.
Ocorre que o pensamento ocidental hegemônico é regido pela máxima cartesiana que, de acordo com Louw (1998), compreende o ser humano como ser isolado da comunidade em que vive, ou seja, o indivíduo cartesiano existe a priori separadamente e independentemente do restante da comunidade e da sociedade, o indivíduo seria concebido assim sem a necessidade de o outro ser concebido. $\mathrm{O}$ Ubuntu (concepção política, filosófica e humana de resistência à opressão e ao Apartheid na África do Sul) contradiz a concepção cartesiana do indivíduo e contribui para 0 respeito às particularidades, individualidades e historicidades do outro, pois para tal concepção do ser humano os indivíduos existem apenas nas suas relações com os outros e como tais relações mudam também mudam as características individuais. Assim, para o Ubuntu "uma pessoa é uma pessoa através das demais pessoas".

A compreensão da dignidade da pessoa humana e de seus direitos, historicamente, tem sido fruto do sofrimento moral e da dor física. Os homens recuam, horrorizados, a cada grande surto de violência, à vista da 


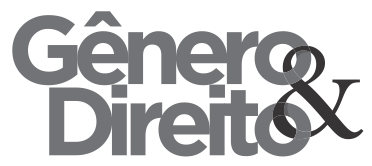

ignomínia que se abre diante de seus olhos:

o remorso pelas torturas, pelos massacres coletivos, pelas mutilações em massa e pelas explorações alvitantes faz nascer nas consciências, então purificadas, a exigência de regras novas que estejam aptas a garantir uma vida mais digna para todos (COMPARATO, 2010).

A despeito dessas manifestações de hostilidade e intolerância para com os Diferentes serem recorrentes, a compreensão da igualdade antropológica dos povos foi aumentando gradativamente, ainda que ficando confinada aos segmentos artísticos, científicos, religiosos e intelectuais das respectivas sociedades (KEINERT, 2012). O termo dignidade aponta para dois aspectos análogos, mas distintos: aquele que é dirigido à vida das pessoas, ao direito e à possibilidade que têm as pessoas de viver uma vida digna; e outro que é inerente à pessoa, pelo simples fato de ser/nascer pessoa humana (NUNES, 2010).

Para Comparato (2006), em sua totalidade, os direitos humanos - direitos civis e políticos, direitos econômicos, sociais e culturais, direitos dos povos, bem como os direitos de toda a humanidade
Céco do Núcleo de Estudos e Pesquisas sobre Gênero e Direito Centro de Ciências Jurídicas - Universidade Federal da Paraíba V. 6 - $\mathrm{N}^{\circ} 02$ - Ano 2017 (como o direito ao meio ambiente sadio) representam a cristalização do princípio, supremo, da dignidade humana. Neste mesmo sentido, para Guerra (2013, p. 41) “[...] os direitos da pessoa humana $[\ldots]$ têm por escopo resguardar a dignidade e condições de vida minimamente adequadas do indivíduo, bem como proibir excessos que porventura sejam cometidos por parte do Estado ou de particulares".

O significado ético-jurídico da dignidade da pessoa humana compreende todo o catálogo aberto dos direitos humanos, em sua permanente interação dialética e indivisibilidade, abarcando valores que preponderam e se contradizem dependendo das singularidades culturais de cada grupo social e do momento histórico, tais como os direitos de primeira geração - vida, propriedade, igualdade, liberdade -, segunda geração - educação, saúde, moradia, trabalho, assistência social -, terceira geração - preservação do patrimônio histórico, cultural e artístico, proteção ao meio ambiente - e de quarta geração - paz, tutela em face da biotecnologia, direitos de minorias, proteção perante a globalização econômica - (SOARES, 2010). 


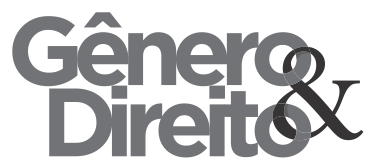

Porém, o reconhecimento da igual dignidade da mulher, em relação ao homem, não foi conquista longínqua. As Declarações internacionais que tratam dos direitos humanos das mulheres são textos recentes, que começam a surgir, no âmbito das Nações Unidas, apenas no final da década de 1970; muito embora as mulheres tenham assumido papéis decisivos nas lutas contra o escravismo, contra o racismo, contra o sexismo, bem como atuaram decisivamente em diversas guerras (como a primeira e a segunda guerra mundial), bem como durante as revoluções francesa, mexicana e russa. Neste sentido, o reconhecimento da igual dignidade das mulheres surge tardiamente na história dos direitos humanos, tendo tais direitos muito que avançar neste âmbito, para que essa igual dignidade possa, enfim, tornar-se realidade materializada na vida de todas as mulheres, sejam elas Negras, trabalhadoras, moradoras de favelas, ou quaisquer que sejam as suas condições.

\section{DIREITOS DAS MULHERES: EXCLUSÃO, UNIVERSALISMO E INCLUSÃO}

Cédico do Núcleo de Estudos e Pesquisas sobre Gênero e Direito Centro de Ciências Jurídicas - Universidade Federal da Paraíba V. 6 - $\mathrm{N}^{\circ} 02$ - Ano 2017

A desigualdade entre homens e mulheres é um traço marcante e presente na maior parte das sociedades, senão em todas. Essa desigualdade, na maior parte da história, não foi nem escamoteada nem camuflada; mas foi assumida como um reflexo da natureza diferenciada dos dois sexos e necessária para o progresso e a sobrevivência da espécie. O pensamento feminista, ao recursar essa compreensão e denunciar a situação das mulheres como efeito dos padrões de opressão, caminhou para uma crítica ampla do mundo social, que impede a ação autônoma de muitos de seus integrantes e reproduz assimetrias (MIGUEL, 2014a). As mulheres querem ser cidadãs, mas a ideia de cidadania foi construída tendo como base a posição do homem (em particular, do homem branco e proprietário) numa sociedade marcada por desigualdades de raça, de classe e de gênero (MIGUEL, 2014b).

$\mathrm{Na}$ Revolução Francesa, as mulheres foram, essencialmente, ativas como representantes de sua classe, e não do seu sexo. Elas protestaram, marcharam, alistaram-se no exército e formaram clubes de mulheres, mas não como feministas, com um programa claro para os direitos das mulheres. A Revolução Francesa, em 


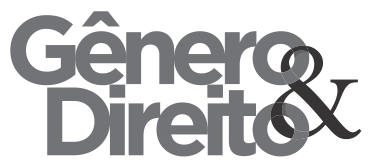

última instância, conquistou pouco para as mulheres, de forma geral, e muito menos ainda para as mulheres pobres (GOLDMAN, 2014).

Ainda durante a segunda metade do século XIX, a natureza das diferenças entre a mulher na nova situação de dependência econômica e na sua antiga situação de inferioridade não eram muito grandes. Na construção social acerca do sexo feminino e na economia, o homem era o sexo dominante, as mulheres eram seres humanos de segunda classe, pois as mesmas não tinham direitos de cidadania, não podendo intitulá-las até mesmo como cidadãs de segunda classe (HOBSBAWM, 1989).

De maneira irônica, a noção de direitos humanos abriu, inadvertidamente, a porta para formas mais virulentas de racismo, antissemitismo e sexismo. As afirmações gerais sobre a igualdade natural de toda a humanidade suscitavam asserções globais acerca da diferença natural, produzindo um opositor aos direitos humanos, ainda mais sinistro e poderoso do que os tradicionalistas. As novas formas de antissemitismo, racismo e sexismo ofereciam explicações para as diferenças naturais baseadas em
Cico do Núcleo de Estudos e Pesquisas sobre Gênero e Direito Centro de Ciências Jurídicas - Universidade Federal da Paraíba V. 6 - No 02 - Ano 2017 204 características biológicas. Os judeus não eram apenas os assassinos de Jesus, mas a sua inferioridade inerente ameaçava macular, por meio da miscigenação, a pureza dos brancos. Os negros já não eram inferiores por serem escravos, pois mesmo quando a abolição da escravatura avançou pelo mundo, o racismo se tornou mais venenoso. As mulheres, por sua vez, não eram simplesmente menos racionais que os homens, por serem menos educadas, mas a sua biologia as destinava à vida doméstica e privada, tornando-as inadequadas para as profissões, os negócios e a política. Nessas novas doutrinas biológicas, as mudanças no meio ambiente ou a educação jamais poderiam alterar as estruturas hierárquicas inerentes à natureza humana (HUNT, 2009).

As promessas de igualdade, liberdade e autodeterminação individual, os grandes valores da Revolução Francesa, pronunciados como direitos universais e destinados às mulheres, acabam por ser traídos por muitas mulheres, pois todos estes direitos dependem da posse do dinheiro e da propriedade. A igualdade é a do dinheiro. A liberdade é a dos que detêm o dinheiro. A autodeterminação é a liberdade de escolha no supermercado. 


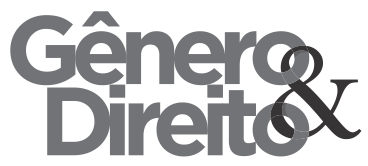

Num sistema mundial baseado na exploração, algumas mulheres são mais iguais que outras (MIES, 1993b).

A Declaração de 1789, da França, declarava os direitos do homem, entendido, exclusivamente, como gênero masculino, e o único direito que era considerado inviolável e sagrado era a propriedade privada (TRINDADE, 2011). Daí o seu caráter classista e sexista; sexista, se não por positivar uma desigualdade formal entre os sexos, mas por omitir-se da proteção às diferenças de gênero.

A partir da Declaração Universal de 1948, começa o desenvolvimento do Direito Internacional dos Direitos Humanos, mediante a adoção de tratados internacionais que visam à proteção dos direitos fundamentais. No âmbito das Nações Unidas, forma-se o sistema global de proteção dos direitos humanos, coexistindo dentro dele os sistemas especial e geral de proteção dos direitos humanos, como sistemas de proteção que se complementam (PIOVESAN, 2014).

O sistema de geral de proteção (como os pactos internacionais de direitos econômicos, sociais e culturais e de direitos civis e políticos de 1966) tem por
Céco do Núcleo de Estudos e Pesquisas sobre Gênero e Direito Centro de Ciências Jurídicas - Universidade Federal da Paraíba V. 6 - $\mathrm{N}^{\circ} 02$ - Ano 2017

sujeito toda e qualquer pessoa, concebida em sua generalidade e abstração. Já o sistema especial de proteção (convenções internacionais que buscam responder a determinadas violações de direitos humanos, como a discriminação contra a mulher, a discriminação racial, a violação dos direitos da criança, etc.) realçou a especificação do sujeito de direito, assim o sujeito passa a ser visto em sua concreticidade e especificidade (ex.: protegem-se as crianças, as mulheres, os grupos étnicos minoritários etc.) (PIOVESAN, 2014).

A Década da Mulher, das Nações Unidas, estava baseada no pressuposto de que a posição econômica das mulheres decorreria de uma difusão e expansão do processo de desenvolvimento. No entanto, no final da Década, ficou claro que o problema era o próprio desenvolvimento. O subdesenvolvimento cada vez maior das mulheres não era devido à participação inadequada e insuficiente no desenvolvimento; mas, devia-se mais a uma participação, forçada e assimétrica, na qual eram excluídas dos benefícios e suportavam os custos. Porém, o papel da mulher no abastecimento do sustento e na regeneração da vida humana tem 


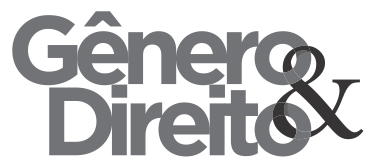

significado que o impacto negativo sobre as crianças tem sido amplificado pelo impacto destrutivo do atual modelo de crescimento econômico sobre as mulheres (SHIVA, 1993).

A cultura ocidental, moderna, e a ética que ela engendra tem sido masculina e com poucas possibilidades de inclusão da mulher. Ao criticar a ideia de uma natureza humana abstrata e de uma prática moral de inspiração patriarcal, a pósmodernidade coloca-se na contramão dessa tendência. Vive-se, hodiernamente, um momento em que o modelo social cartesiano está sendo colocado em questão, juntamente com muitas formas de desigualdade social. Neste processo, o movimento feminista tem sido importante, ao reformular e repensar as relações de gênero, facilitando a mulheres e homens vivenciar valores mais democráticos. Também procura romper com a separação entre o emocional e o racional, que tem servido para dar identidade às pessoas e estabelecer possibilidades e limites, investindo em parâmetros em que a lógica seja a do equilíbrio e da inclusão. Pois, é sabido que as desigualdades baseiam-se em estereótipos e preconceitos culturais, que são necessários à manutenção dos
Cécico do Núcleo de Estudos e Pesquisas sobre Gênero e Direito Centro de Ciências Jurídicas - Universidade Federal da Paraíba V. 6 - No 02 - Ano 2017 206
(PASSOS, 2014).

As epistemologias feministas desafiaram o modelo de ciência "ocidental" e a "modernidade" (como um modelo a ser seguido por todos aqueles que vinham "atrás da tradição"). Elas partiram do pressuposto de que a epistemologia hegemônica ou dominante é masculina, muito embora o nome usado não seja esse, mas o de ciência objetiva e neutra e de conhecimento desinteressado, realçando assim a política sexual do conhecimento. Tais epistemologias têm sido enquadradas por um paradigma patriarcal dominante, a partir do qual a ciência moderna foi construída. A epistemologia masculina tornou invisíveis, ainda, outras perspectivas de compreensão e outros tipos de conhecimento que estão emergindo sob o rótulo de epistemologias feministas. As epistemologias feministas contribuíram ainda para desalojar o mito de que a ciência estaria vacinada e purificada contra a infecção da sexualidade e da diferença sexual (MIGNOLO, 2004).

É nesse contexto que foi aprovada, em 1979, a Convenção sobre a Eliminação de todas as Formas de Discriminação 


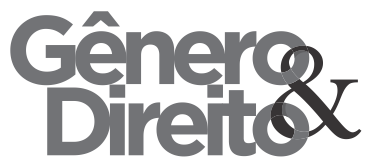

contra a Mulher, que possui o objetivo de erradicar a discriminação contra a mulher e as suas causas, bem como estimular estratégias de promoção da igualdade. Reconhece que às políticas públicas devem ser aliadas as vertentes legais repressivo-punitivas e positivopromocionais (PIOVESAN, 2014).

A mudança de paradigma que se começa a vislumbrar tem grande dívida com o movimento feminista (PASSOS, 2014). Hall (2015) aponta que o feminismo teve uma relação direta com o descentramento conceitual do sujeito sociológico e cartesiano:

- Questionando a distinção clássica entre o "público" e o "privado", o "dentro" e o "fora". "O pessoal é político" era o slogan do feminismo;

- Trazendo para a contestação política novas arenas da vida social: a sexualidade, a família, a divisão doméstica do trabalho, o cuidado com as crianças, o trabalho doméstico, etc.;

- Enfatizando, como questão social e política, a forma segundo a qual somos produzidos e formados como sujeitos genéricos. Politizou
Cico do Núcleo de Estudos e Pesquisas sobre Gênero e Direito Centro de Ciências Jurídicas - Universidade Federal da Paraíba V. 6 - $\mathrm{N}^{\circ} 02$ - Ano 2017

a identidade, a subjetividade e o processo de identificação (mães/pais, filhos/filhas, homens/mulheres);

- Tendo começado como um movimento que contesta a posição social das mulheres, expandiu-se para incluir a formação das identidades de gênero e sexuais;

- Questionando a noção de que as mulheres e os homens eram parte de uma mesma identidade - a "humanidade" -, substituindo-a pela diferença sexual.

A inclusão da política da identidade, marcada pela diferença sexual, no âmbito do direito internacional dos direitos humanos é uma conquista que foi indubitavelmente influenciada pelos movimentos de mulheres. Neste sentido, a permanência e a expansão dos movimentos feministas demonstra que ainda se faz necessário desconstruir os paradigmas patriarcais que ainda influenciam a subjetividade e a sexualidade, refletindo na estigmatização das mulheres diante da produção e/ou aplicação do direito. 


\section{A SEXUALIDADE $\mathrm{E}$ A} SUBJETIVIDADE AGRESSIVA

Nos campos da saúde, da violência, da educação, no terreno jurídico etc. há uma consciência da situação capaz de definir os direitos humanos no feminino. Os portadores desta consciência lutam pela concretização de uma cidadania ampliada, de direitos humanos para os Negros, mulheres e pobres. O respeito ao outro é o núcleo desta nova concepção de vida em sociedade. Respeitar o outro é um dever do cidadão, seja este outro Negro, pobre, mulher (SAFFIOTI, 2015).

A Convenção sobre a Eliminação de todas as formas de Discriminação contra a Mulher, de 1979, foi um passo importante para a proteção da dignidade humana. Porém, tal documento ainda não contemplava de forma explícita a questão da violência, que só veio a ser definida, em 1993, na Declaração sobre a Eliminação da Violência contra a Mulher. Tal texto estabelece que a violência contra a mulher é qualquer ato de violência de gênero, inclusive as ameaças de tais atos, que resulte, ou possa resultar, em privação da
Céco do Núcleo de Estudos e Pesquisas sobre Genero e Direito Centro de Ciências Jurídicas - Universidade Federal da Paraíba V. 6 - No 02 - Ano 2017

208

liberdade ou coerção, podendo ocorrer na esfera privada ou na esfera pública (GUERRA, 2014).

A noção de gênero, contida na Declaração de 1993, aponta que gênero é uma construção sociocultural do feminino e do masculino, sendo atribuídos papéis diversos para mulheres e homens na sociedade, estabelecendo deveres e direitos, com estrutura hierarquizada e estratificada. A violência de gênero é tomada como uma forma de agir da sociedade. Neste sentido, a Declaração prevê, ainda, que os Estados devem eliminar e condenar a violência contra a mulher, não podendo invocar tradições, costumes ou questões de natureza religiosa para afastar suas obrigações com relação à eliminação da violência (GUERRA, 2013).

Dentre as violências de gênero, a que fere a dignidade sexual é uma das mais agressivas contra a dignidade humana, representando a submissão e utilização sexual.

À luz dos preceitos enunciados nos instrumentos do direito internacional dos direitos humanos, pode-se concluir, sem buscar um elenco exaustivo, que os direitos sexuais incluem: a) o direito a ter 


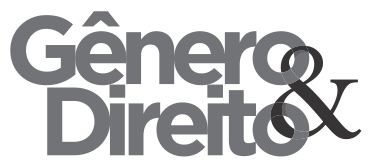

controle sobre seu próprio corpo; b) o direito a decidir livre e responsavelmente sobre sua sexualidade; c) o direito a receber educação sexual; d) o direito à privacidade; e) o direito a viver livremente sua orientação sexual, sem sofrer discriminação, violência ou coação; f) o direito a fruir do progresso científico e a consentir livremente à experimentação, com os devidos cuidados éticos recomendados pelos instrumentos internacionais; g) o direito de acesso às informações e aos meios para desfrutar do mais alto padrão de saúde sexual (PIOVESAN; PIROTTA, 2014).

Em sua análise dos casos de violações dos direitos humanos presentes em casos demandados perante a Comissão Interamericana de Direitos Humanos, entre 1970 e 2008, Gonçalves (2013) aponta que as questões de gênero transparecem quando as mulheres predominam como $68,4 \%$ das vítimas nos casos relativos aos direitos sexuais e reprodutivos, enquanto os homens prevalecem como 46,4\% das vítimas nos casos relativos aos direitos de propriedade e liberdade. Sendo que os casos em que homens e mulheres aparecem simultaneamente como vítimas de violações de direitos sexuais e reprodutivos representam apenas 28,9\% do total, enquanto que apenas em $1 \%$ dos casos as vítimas são exclusivamente do sexo masculino, apenas. Já com relação aos direitos de propriedade e liberdade, em 40,3\% dos casos as vítimas são de ambos os sexos, sendo que em apenas $7,7 \%$ dos casos as vítimas são apenas do sexo feminino, e em 5,3\% dos casos não consta o sexo das vítimas.

Tal situação de assimetria entre homens e mulheres é o reflexo da exclusão e da desigualdade baseadas no gênero, que alimentam e são alimentadas pela concentração desproporcional da propriedade e do poder sociopolítico nas mãos dos homens, sendo, por isso mesmo, uma construção histórico social, e não de ordem biológica.

A opressão é o aproveitamento de desigualdades para submeter e deixar em desvantagem um grupo social, com base em diferenças sexuais, nacionais, raciais ou de outro tipo, o que gera uma situação de discriminação social, cultural e eventualmente econômica, bem como de desigualdade de direitos (CARRASCO; PETIT, 2012). 
No âmbito penal, por exemplo, de

acordo com Andrade (2004) o funcionamento ideológico do sistema de justiça criminal - a circulação da ideologia penal dominante no senso comum ou entre a opinião pública e entre os operadores do sistema - perpetua o ilusionismo, que justifica socialmente a importância da sua existência, ocultando suas reais e invertidas funções. Assim, apresenta-se uma eficácia simbólica que sustenta a eficácia instrumental invertida. Esta eficácia invertida significa que a função real e latente do sistema não é o combate (a redução ou a eliminação) da criminalidade, protegendo bens jurídicos universais e gerando segurança jurídica e pública, mas, de forma contrária, construíla estigmatizante e seletivamente, e neste processo reproduzir, ideológica e materialmente, as assimetrias sociais e as desigualdades (de gênero, de classe e de raça).

O estigma possui duas dimensões: uma objetiva (um uso, um sinal, a origem, a doença, a embriaguez, o sexo, a cor da pele, a nacionalidade, a pobreza, a religião, a orientação sexual, a deficiência mental ou física etc.) e uma subjetiva (a atribuição negativa ou ruim que se faz a estes estados). A derivação de regras para os estigmatizados funciona de maneira a prejudicar-lhes a vida cotidiana e a tornar enfraquecido o convívio humano, pois os supostos "normais" saem também lesionados da relação. São falsas regras e que não possuem nexo com a realidade. As marcas das mulheres geram para elas tratamentos distintos do homem médio, uma vez que são decorrências naturais de regras práticas criadas para elas. Como não são regras admitidas juridicamente, mas existentes, constituem metarregras associadas aos estigmas. Os estigmas atuam como regras de discriminação, uma vez que indissociáveis delas (BACILA, 2015).

A equidade de gênero é violada desde uma perspectiva de exclusão (esta que é cultural, simbólica, permeada por estigmas, estereótipos, preconceitos e discriminação), mas, também, desde uma perspectiva de desigualdade (esta que é econômica, tendo em vista que o patriarcado, como entende a perspectiva marxista, é alimentado por uma concentração da propriedade sob o poder dos homens). Neste sentido, a justiça de gênero deve ir além da simples redistribuição de poder econômico, 


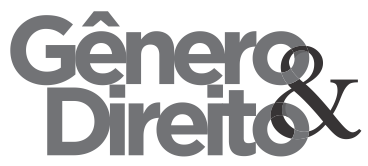

político e social, implicando, também, uma mudança de paradigmas.

Uma das condições para a reconstrução intercultural dos direitos humanos é a aceitação do seguinte imperativo transcultural, de acordo com Santos (2010, p. 462): “[...] temos o direito a ser iguais quando a diferença nos inferioriza; temos o direito a ser diferentes quando a igualdade nos descaracteriza". Provavelmente, todas as comunidades culturais, ou ao menos as mais complexas, distribuem os grupos sociais e os indivíduos segundo dois princípios de pertença hierarquizada - hierarquização entre diferenças consideradas primordiais, expressa no sexismo e no racismo, por exemplo; trocas desiguais entre grupos ou indivíduos formalmente iguais, sendo a exploração capitalista dos trabalhadores um exemplo paradigmático - e segundo concepções rivais de diferença e de igualdade. Em tais circunstâncias, nem o reconhecimento da diferença nem o reconhecimento da igualdade serão condição suficiente de uma política multicultural emancipatória. $\mathrm{O}$ multiculturalismo progressista pressupõe, portanto, que o princípio do reconhecimento da diferença seja ódico do Núcleo de Estudos e Pesquisas sobre Gênero e Direito Centro de Ciências Jurídicas - Universidade Federal da Paraíba V. 6 - No 02 - Ano 2017 prosseguido de par com o princípio da igualdade (SANTOS, 2010).

A equidade de gênero demanda um direito que vai além de uma melhor distribuição dos postos e lugares que o homem ganhou na sociedade. A política da diferença leva a indagar, além do essencialismo, a forma como, na divisão dos sexos, o enigma do gênero e do erotismo se configura, como se constitui o caráter simbólico do ser humano onde se inscreve a ordem do desejo, que marca sempre o problema da justiça humana e da dominação. Além dos direitos à igualdade diante da diferença dos sexos, além da divisão (natural/simbólica) dos seres humanos coisificados através de sua distribuição em gêneros (neutro/feminino/masculino), designados pela diferença entre o "a" e o "o", o gênero se inscreve na ordem do erotismo, como questão que corresponde ao ser, e ao direito ao ser (LEFF, 2006). "A reivindicação ecofeminista procura recuperar, para homens e mulheres, o sentido de uma feminilidade perdida ao equiparar-se e igualar-se ao homem dentro dos códigos da razão que separam e dominam o homem, a mulher, a cultura e a natureza” (LEFF, 2006, p. 331). 
A condição de gênero, em parte, derivada do fato de abrigar no próprio corpo a reprodução da espécie, torna-se um fardo enorme quando recai individualmente sobre a mulher. $\mathrm{O}$ fenômeno da maternidade precoce vem agravando a responsabilidade das mulheres. Esse fenômeno está ligado à banalização da sexualidade, com a sensualização precoce da infância, e ao fato de a casa e/ou a escola não ser mais o lócus privilegiado de conformação da subjetividade. É um espaço público cada vez mais subordinado à lógica privada de mercado que se faz presente na formação subjetiva, estimulando o individualismo, como se vê nos outdoors, nos meios de comunicação de massa e nos shopping centers. A feminização das responsabilidades (e da pobreza) torna a vida dramática, num quadro cultural de machismo, onde as mulheres recebem salários inferiores aos dos homens; onde o trabalho doméstico não tem garantia de direitos e não é reconhecido por todo o significado que comporta para a reprodução geral da sociedade. A questão de gênero coloca desta maneira a necessidade de repensar as relações sociedade-natureza, não apenas com a natureza externa à sociedade, mas, também, com a natureza inscrita na espécie humana enquanto diferença biológica de macho e fêmea, colocando o desafio de reinventar, pela política e pela cultura, novas relações entre o masculino e o feminino (PORTO-GONÇALVES, 2013).

O corpo é também o que se diz dele, ou seja, o corpo é construído pela linguagem. A linguagem não apenas reflete o que existe, ela própria cria o existente. Com relação ao corpo, ela tem o poder de classificá-lo, nomeá-lo, definirlhe normalidades e anormalidades. Porém, tais representações não são nem universais, nem fixas. São, ao contrário, sempre efêmeras, temporárias, inconstantes e conforme o tempo/lugar onde esse corpo vive, circula, expressa-se, produz-se e é produzido, elas variam. A escola, mas não apenas ela, visto que há várias outras pedagogias em circulação, tais como músicas, filmes, livros, revistas, imagens e propagandas, estão a dizer de nós, seja pelo que ocultam ou pelo que exibem. Dizem de nossos corpos, de forma tão sutil que nem mesmo percebemos o quanto somos produzidas/os e 
capturadas/os pelo que lá se diz (GOELLNER, 2013).

O processo de "fabricação" dos sujeitos é continuado, quase imperceptível, geralmente muito sutil. Antes de tentar percebê-lo pela leitura dos decretos ou das leis que regulam e instalam as instituições ou percebê-los nos discursos solenes das autoridades (embora tais instâncias também façam sentido), o olhar deve se voltar para as práticas cotidianas em que todos os sujeitos se envolvem. São as práticas comuns e rotineiras, as palavras e os gestos banalizados que precisam se tornar alvo de atenção renovada, de questionamento e de desconfiança. A tarefa mais urgente talvez seja a de desconfiar do que é tomado como "natural" (LOURO, 2014).

As representações das relações de gênero nas quais a mulher é objetificada $e$ humilhada, tratada como menos que humana, pois é definida como um instrumento para a satisfação dos desejos de outros, podem contribuir, mesmo que de forma difusa, para a violência contra as mulheres, bem como para a aceitação dessa violência. Contribuindo, ainda, para mantê-las em posições de maior vulnerabilidade material e simbólica. Sua definição como objetos sexuais exclui, de maneira potencial, outras definições e a consideração de outras capacidades. A representação de representações hierarquizadas do feminino e do masculino não se esgota, socialmente, em suas expressões sexualizadas e eróticas, mas ganha forma de constrangimentos, discriminação e desrespeito que podem ser invisíveis e sutis, mas que impactam nas escolhas e oportunidades possíveis para as mulheres, bem como em sua integridade psíquica e física. Por outro lado, puritanismo, repressão e silenciamento das vivências das mulheres definiram, ao longo da história, diversas formas do domínio masculino. Trata-se, mais uma vez, de buscar arranjos que permitam o avanço, simultaneamente, na direção da autonomia das mulheres e na defesa da igualdade de gênero (BIROLI, 2014).

$\mathrm{Se}$ as mulheres e os homens começarem a entender a relação sexual física como uma interação amorosa e carinhosa consigo próprio, com a natureza e com os seus parceiros, este relacionamento levaria a uma nova compreensão da sexualidade - não como uma conduta agressiva e egoísta, mas como uma faculdade humana de ligação a 
nós mesmos, uns aos outros, à Terra e a todos os seus habitantes. É essencial o desenvolvimento desta nova ecologia sexual e reprodutiva, se as mulheres tiverem a possibilidade de manter a sua dignidade humana; é mais importante para os homens que, na sociedade patriarcal e militarista, são ensinados a identificar a sua sexualidade com a agressão. Esta que é dirigida não apenas contra os seus parceiros sexuais, mas também contra si mesmos. Este novo entendimento de sexualidade não patriarcal só se pode desenvolver com alterações na divisão sexual da economia, da política e do trabalho. Apenas quando os homens começarem a partilhar seriamente o cuidado das crianças, dos fracos, da natureza e dos velhos, quando reconhecerem que o trabalho de subsistência que preserva a vida é mais importante que o trabalho para o dinheiro, serão capazes de desenvolver uma relação responsável, carinhosa e erótica com os seus parceiros, sejam eles mulheres ou homens (MIES; SHIVA, 1993).

A promoção do extenso rol de direitos humanos, em seu compromisso com a proteção da dignidade humana, demanda o urgente reconhecimento de inúmeras violações de direitos baseadas nas hierarquias de gênero. Neste sentido, a dignidade sexual resta fragilizada quando ao homem é imposto o desenvolvimento de uma sexualidade/subjetividade agressiva, enquanto que às mulheres é uma imposta uma sexualidade submissa. Há a necessidade de combater diversos estigmas que violentam, cotidianamente, a dignidade/subjetividade das mulheres, tais como os de gênero, de classe e de raça.

\section{A DIGNIDADE SEXUAL NO DIREITO PENAL BRASILEIRO: UMA ABORDAGEM HISTÓRICA}

A história das mulheres é, sobretudo, a história da instalação da sua repressão e da ocultação desta. Uma vez que a ocultação é parte da repressão: não há ciência neutra e não há acaso. Por isso, a história das mulheres só começa a emergir do silêncio depois que as feministas tentam rompê-lo e começam a explorar um passado espantoso (MICHEL, 1982). Esse passado espantoso é permeado pela construção de representações preconceituosas e discriminatórias acerca do corpo feminino e da feminilidade. $\mathrm{O}$ direito, por exemplo, fornece inúmeras 


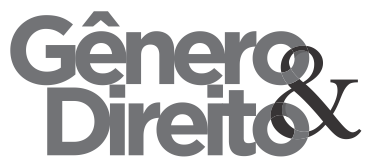

fontes históricas acerca da "legitimação" jurídica da hierarquização que inferioriza o corpo da mulher, seja em relação ao homem, seja em relação às demais mulheres que eram inferiorizadas umas em relação às outras, em consequência dos valores, negativos, impostos pela moral patriarcal.

O biopoder, de suma importância na reflexão de Foucault, que penetra na carne e é capaz de determinar a constituição do estar e do ser do indivíduo, e de forma calculista determina suavemente os conceitos religiosos, educacionais, morais, jurídicos, políticos e sexuais vigentes, pode ser considerado como a manifestação mais clara da ação concreta docilizadora da microfísica do poder (BITTAR, 2011). Neste sentido, a ideologia patriarcal e a sua moral podem atuar influenciando o mundo jurídico, como ocorreu na edição do Código Penal Brasileiro, de 1940, e já ocorria antes mesmo da edição deste texto legal.

Na década de 1920, fundamentado no Código Criminal de 1890, Gusmão (1921, p. 93) afirmava que:

A moral sexual é a base, o substractum de todo o edifício da moral, ou, antes, é a sua viga mestra ; ella se dilue, se mescla, invade e dico do Núcleo de Estudos e Pesquisas sobre Gênero e Direito Centro de Ciências Jurídicas - Universidade Federal da Paraíba V. 6 - No 02 - Ano 2017

215

influencía, mais ou menos directa ou indirectamente, mediata ou inmediatamente, em fórma inicialmente propulsora ou reflexa, todos os mais campos da moral social.

A marca de uma concepção moral já ultrapassada, derivada claramente da ideologia patriarcal, que, fundada nas relações de subordinação entre os sexos, reproduz as relações mais gerais de exclusão e dominação características de formações sociais fundadas na desigualdade, esteve presente na Parte Especial do Código Penal Brasileiro de 1940, em uma série de dispositivos especialmente os que tratam da definição dos crimes contra a família e dos crimes contra os costumes - (KARAM, 1995).

\section{A percepção da penetração} histórica da moral patriarcal no direito penal sexual é facilitada quando da análise de qualquer um dos crimes tratados neste âmbito do direito penal. O crime de estupro, por exemplo, permite perceber a forma como os legisladores, o judiciário e os doutrinadores nomeavam, classificavam e hierarquizavam os corpos femininos segundo os critérios de "mulher virgem", "mulher honesta" e "prostituta" ou "meretriz". 


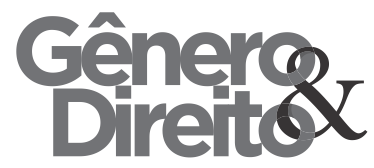

De acordo com Gusmão (1921, p. 119): "Estupro é o acto pelo qual o individuo abusa de seus recursos physicos ou mentaes para, por meio da violencia, conseguir ter conjuncção carnal com a sua victima, qualquer que seja a seu sexo". A violência é entendida assim como necessária à prática do estupro, tendo em vista o estupro ser um crime que fere profundamente a dignidade humana. Não há respeito aos direitos humanos quando a dignidade humana é violada.

De acordo com Bitencourt (2015, p. 50-51):

[...] as mudanças contempladas pela Lei n. 12.015/2009, reunindo os antigos crimes de estupro (art. 213) e atentado violento ao pudor (art. 214), para unificá-los em um conceito mais abrangente de estupro, não têm o condão de alterar o significado do vocábulo conjunção carnal, que continua sendo a cópula vagínica, diversa de outros atos de libidinagem.

$\mathrm{Na}$ realidade, a partir desse diploma legal, passamos a ter duas espécies distintas de estupro, quais sejam: a) constranger à conjunção carnal; b) constranger à prática de outro ato libidinoso.

O direito penal brasileiro sempre esteve carregado de um forte conteúdo moral, uma moral patriarcal. Exemplo disso é o fato de por tanto tempo ter se estabelecido a figura da "mulher honesta" e dos "crimes contra os costumes" no dico do Núcleo de Estudos e Pesquisas sobre Gênero e Direito Centro de Ciências Jurídicas - Universidade Federal da Paraíba V. 6 - No 02 - Ano 2017 216

direito penal brasileiro, que, atualmente, trata dos crimes que atentam contra a dignidade sexual. Porém, tal moral é, também, historicamente, racista, por isso: "O escravo não era considerado como capaz de ser sujeito passivo de tal delito. Se o estuprum, na pessoa do escravo, era praticado por outrem que não o senhor, o patrão, este tinha a faculdade de usar da actio de lege Aquillia ou de servu corrupto" (GUSMÃO, 1921, p. 121).

O Brasil era regido pelo direito português (Ordenações Filipinas, leis, decretos, regimentos etc.), antes do advento do "Codigo Criminal do Imperio", de 1830. O crime de estupro era punido com a morte, ainda que o criminoso cassasse com a sua vítima. Durante a vigência do "Codigo Criminal Brasileiro", o crime de estupro passou a diferenciar a pena, tratando como crime punido com pena de reclusão de 3 a 12 anos o estupro de "mulher honesta" e crime punido com pena de reclusão de um mês a doze o estupro de "prostituta". O Codigo de 1890 , por exemplo, estabelecia a pena para quem estuprasse uma "mulher virgem" ou "honesta" de 1 a 6 anos de prisão, sendo que quando a vítima fosse uma "mulher pública" ou "prostituta" a pena seria de 6 
meses a dois anos de prisão (GUSMÃO, 1921).

Segundo o seu entendimento, machista, e que não encontra aceitação social, atualmente, Gusmão (1921, p. 196197) afirma que:

A mulher casada não pode ser sujeito passivo do crime de estupro. A conjuncção carnal é um dos deveres que, juridicamente, assistem á esposa, comquanto bem certo seja não ser, se tornaria desnecessario ponderar n'uma obra juridica, o fim único do consorcio.

$\mathrm{O}$ marido que prefere a violencia a outros meios para obter a satisfação d'este e de outros deveres, falha aos mais comesinhos principios de cavalheirismo, constata e revela um temperamento animal não refreiado pela educação, pelo sentimento e pela moral, mas o acto, na hypothese, é da esphera da moral e não do direito penal e fazemos a restricção porque tal facto, pelas circunstancias que possa assumir, pela sua reiteração, brutalidade estulta e injustificavel, poderá, quiçá, bem é de ver, assumir aspectos attinentes ao direito civil.

Na visão de Gusmão, o fim único do casamento seria o sexo, e a mulher, tendo como um de seus deveres "a conjunção carnal", não seria mais do que uma necessidade biológica do homem. E o homem sendo violento para buscar a satisfação deste “dever", apenas, falharia em reproduzir os princípios mais básicos do cavalheirismo, agindo guiado pelo seu instinto animal, não referenciado pela moral, pelo sentimento e pela educação.

Essa era a visão de Gusmão acerca do Código de 1890, uma visão patriarcal, tal como a do próprio Código.

Já acerca do Código de 1940, Noronha (1943, p. 15) escreveu que o “[...] bem jurídico que o art. 213 protege é a liberdade sexual da mulher; é o direito de dispôr do corpo; é a tutela do critério da eleição sexual de que goza na sociedade". Porém, ele faz tal assertiva permeada por diversos estigmas, alimentados por uma moral patriarcal, desvinculada do princípio da dignidade humana. Mais a frente, em seu texto, Noronha (1943, p. 36) demonstra alguns dos estereótipos que o mesmo alimenta acerca da condição social das mulheres:

A meretriz estuprada, além da violência que sofreu, não sofre qualquer outro dano. Sem reputação e sem honra, nada tem a temer como consequência do crime. A mulher honesta, entretanto, arrastará por todo o sempre a mancha indelevel com que a polui o estuprador máxime se for virgem, caso que assume, em nosso meio, proporções de dano irreparavel. No estupro da mulher honesta há duas violações: contra sua liberdade sexual e contra sua honra; no da meretriz apenas o primeiro bem é ferido.

Greco (2013) afirma que o pensamento machista envolveu a edição do Código Penal de 1940, pois a vítima de 
estupro era considerada culpada de sua própria sorte, por não haver se esforçado o suficiente para evitar a penetração do criminoso, posição que não pode ser sustentada, atualmente, diante das alterações sofridas pelo Código Penal.

O controle social do corpo feminino pela figura da autoridade masculina (o marido, o clérigo, o pai) é um tema recorrente no imaginário coletivo. Ainda hoje, as roupas femininas são alvo de discussão acerca de sua influência no ânimo de um agressor sexual (ZAPATER, 2015). Neste sentido, a luta das mulheres vem sendo uma luta por identidade, mas também de reconstrução e transformação das identidades históricas que herdaram (DUPRAT, 2015).

Com o advento da modernidade ocidental, as relações de gênero foram deixadas fora do âmbito da justiça. Desde os primeiros teóricos do contrato social, estabeleceu-se uma distinção entre o público e o doméstico. A esfera da justiça é vista como o domínio dos chefes de família, masculinos, responsáveis por criar as bases, legítimas, da ordem social. À mulher, restaram confiadas as tarefas da reprodução, do amor, do cuidado e da criação, desenvolvidas no espaço doméstico. Esse primeiro corte produziu outras dualidades correspondentes: a justiça como o espaço da história e da cultura, da racionalidade e da autonomia, do universal; o lar, como esfera da intimidade e do cuidado, é a-histórico e atemporal, repetindo os ciclos da natureza/vida, é o lugar da dependência, da emoção e do particular (DUPRAT, 2015).

É o resgate das relações de gênero para o âmbito da justiça que vem promovendo diversos avanços no sentido de proteger e promover a dignidade sexual das mulheres. Neste sentido, é a dignidade humana que se tem como fundamento dessa nova representação das mulheres no mundo jurídico, expandindo o rol de direitos humanos para proteger diversas faces da dignidade humana até então desprotegidas contras abusos e graves violações. Para Bitencourt (2015, p. 44): “[...] nada é mais indigno, mais humilhante, mais destruidor do ser humano que a violência sexual, causando profundos traumas em suas vítimas que, por vezes, não conseguem superá-los".

Carvalho (1943) afirma que o Código Penal de 1940 não estabeleceu diferença entre o estupro de prostituta, virgem e mulher honesta. Assim, a 


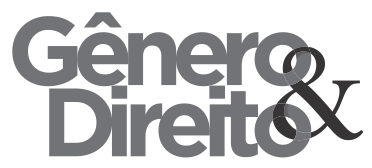

condição social da vítima não constituiria atenuante, ao contrário do que ocorria durante a vigência do código penal de 1980. O mesmo era de opinião de que a inovação feita não parecia justa, visto que, através dela, a mulher honesta e a virgem são colocadas no mesmo pé de igualdade da prostituta, uma vez que o artigo 213 se referia à mulher, de maneira genérica. $\mathrm{O}$ critério diferencial do estupro da mulher virgem, da honesta e da mulher pública ou prostituta, tem sua origem no antigo direito romano. Desde então, essa matéria passou por três fases: $1^{\mathrm{a}}$ - a prostituta não poderia ser sujeito passivo do delito de estupro, dada a sua condição social; $2^{\mathrm{a}}$ - a prostituta passa a figurar como sujeito passivo do delito, tendo, porém, o infrator a sua pena atenuada, devido à condição social da prostituta; $3^{\mathrm{a}}$ - qualquer distinção é finalmente abolida.

De acordo com Rodrigues (2013, p. 29):

Países como a Alemanha, após a reforma de 1973, e a Espanha, depois da reforma de 1989, passaram a tutelar penalmente a liberdade de autodeterminação sexual das pessoas, e não a moral pública.

No Brasil, podem-se citar duas reformas do Código Penal referentes à matéria, ocorridas em 2005 e 2009. A reforma de 2005, perpetrada pela Lei n. 11.106, pode ser considerada um marco para o direito penal sexual. Figuras como a da mulher
Códico do Núcleo de Estudos e Pesquisas sobre Gênero e Direito Centro de Ciências Jurídicas - Universidade Federal da Paraíba V. 6 - No 02 - Ano 2017

219

honesta, ou a da extinção da punibilidade baseada no casamento do autor do delito ou de terceiro com a vítima, há muito criticadas pela doutrina, foram extirpadas do direito brasileiro. [...]

A reforma de 2009, realizada pela Lei n. 12.015, trouxe como grande avanço a alteração da denominação do título de Crimes contra os Costumes para Crimes contra a Dignidade Sexual, tendo em vista o princípio da dignidade humana, substrato de um Estado Democrático de Direito.

Ante o exposto [...] a moralidade se faz presente nos delitos sexuais até os dias de hoje.

O Título VI do Código Penal, com a nova redação que foi dada pela Lei $n^{\mathbf{o}}$ 12.015, de 7 de agosto de 2009, passou a prever os Crimes contra a Dignidade Sexual, modificando a redação anterior, que previa os Crimes contra os Costumes. A expressão Crimes contra os Costumes já não era capaz de traduzir a realidade dos bens que são juridicamente protegidos pelos tipos penais encontrados no Título VI do Código Penal. O foco da proteção deixa de ser a forma como as pessoas deveriam se comportar sexualmente em sociedade, para ser a tutela da dignidade sexual, que é uma das espécies do gênero dignidade humana (GRECO, 2013).

$\mathrm{O}$ bem jurídico dignidade sexual está bem distante dos bons costumes, 
defendidos outrora. A liberdade sexual ${ }^{2}$ é

o bem jurídico a ser tutelado nos delitos sexuais, entre maiores capazes. Desde que essa liberdade sexual seja considerada como forma de exteriorização do princípio da dignidade humana (RODRIGUES, 2013). A Lei n. 12.015/2009 modificou o Título VI do Código Penal, que passou a tutelar a dignidade sexual, vinculada diretamente ao direito de escolha de parceiros e à liberdade, suprimindo a terminologia "crimes contra os costumes", já superada. Reconhece, assim, que os crimes sexuais fraudulentos ou violentos atingem diretamente a liberdade, a personalidade e a dignidade do ser humano (BITENCOURT, 2015). De acordo com Greco (2013, p. 662):

Inicialmente, a proposta legislativa era no sentido de que no Título VI do Código Penal constasse a expressão: Dos crimes contra a liberdade e o desenvolvimento sexual. Embora

2 "Liberdade sexual da mulher significa o reconhecimento do direito de dispor livremente de suas necessidades sexuais ou voluptuárias, ou seja, a faculdade de comportar-se, no plano sexual, segundo suas aspirações carnais, sexuais ou eróticas, governada somente por sua vontade consciente, tanto sobre a relação em si como em relação a escolha de parceiros. Esse realce é importante, pois para o homem parece que sempre foi reconhecido esse direito. Em outros termos, se reconhece que homem e mulher têm o direito de negarem-se a se submeter à prática de atos lascivos
220

tenha prevalecido a expressão Dos crimes contra a dignidade sexual, também podemos visualizar o desenvolvimento sexual como outro bem a ser protegido pelo tipo penal em estudo.

Assim, segundo Greco (2013) os bens juridicamente protegidos pelo Título VI do Código Penal são: a liberdade, a dignidade e o desenvolvimento sexual.

$\mathrm{O}$ ordenamento penal brasileiro estabelece a dignidade sexual como um bem jurídico de extrema relevância a ser protegido. Além da tutela própria à liberdade sexual, os tipos penais que envolvem a sexualidade humana também acabam por proteger outros bens, tais como a vida, a saúde, a dignidade pessoal etc. Isso porque a colocação da dignidade sexual como um bem jurídico a ser tutelado pressupõe o abandono de um modelo voltado a aspectos morais para dar lugar à proteção do ser humano, proteção

ou voluptuosos, sexuais ou eróticos, que não queiram realizar, opondo-se a qualquer possível constrangimento contra quem quer que seja, inclusive contra o próprio cônjuge, namorado(a) ou companheiro(a) (união estável); no exercício dessa liberdade podem, inclusive, escolher o momento, a parceira, o lugar, ou seja, onde, quando, como e com quem lhe interesse compartilhar seus desejos e necessidades sexuais. Em síntese, protege-se, acima de tudo, a dignidade sexual individual, de homem e mulher, indistintamente, consubstanciada na liberdade sexual de cada um e direito de escolha" (BITENCOURT, 2015, p. 48). 


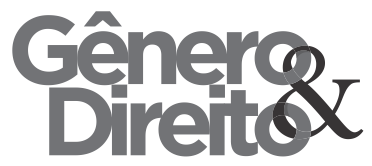

Gênerger
Direits

à dignidade humana. A alteração do nome

de um crime não representa por si só uma mudança sensível; porém, não é isso o que se pode dizer da colocação da dignidade sexual no lugar dos antigos "costumes" tutelados pelo Código Penal (D’ELIA, 2012).

É a dignidade humana que se está a proteger quando se reprimem as violações da dignidade sexual. Para Capez (2010, p. 21): "A tutela da dignidade sexual, portanto, deflui do princípio da dignidade humana, que se irradia sobre todo o sistema jurídico e possui inúmeros significados e incidências". Neste sentido, o direito brasileiro tem caminhado no sentido do reconhecimento de que não há dignidade humana sem dignidade sexual. A maior participação das mulheres na vida política, econômica e social, ainda que desigual, tem provocado mudanças nas desigualdades de gênero, impactando em certa medida os poderes executivo, legislativo e judiciário, que passam a ter um dever de promover a equidade de gênero, em suas respectivas áreas de atuação. A reforma do Código Penal de 1940 é reflexo, além de todas as lutas das mulheres brasileiras, de um movimento internacional pela positivação dos direitos dico do Núcleo de Estudos e Pesquisas sobre Gênero e Direito Centro de Ciências Jurídicas - Universidade Federal da Paraíba V. 6 - No 02 - Ano 2017

221

das mulheres, que tem refletido na publicação de inúmeros Tratados, Declarações e recomendações no âmbito da Organização das Nações Unidas (ONU).

\section{CONSIDERAÇÕES FINAIS}

A dignidade humana é o núcleo essencial do qual emanam todos os direitos humanos, ou seja, o fim dos direitos humanos é a proteção da dignidade humana. Neste sentido são as experiências históricas de violação da integridade física, moral e espiritual dos seres humanos - racismo, sexismo, colonialismo, escravidão etc. - que influenciaram o despertar da consciência ética acerca da necessidade da expansão dos direitos humanos. É a luta contra o sexismo que vai embalar a participação cada vez maior das mulheres pela promoção da sua dignidade sexual

Historicamente, é possível perceber que as mulheres nem sempre foram consideradas sujeitos de direitos humanos. O homem do título da "Declaração dos Direitos do Homem e do Cidadão", de 1789, é o do gênero masculino. A Declaração Universal dos 
Direitos Humanos, de 1948, universaliza os direitos humanos, porém sem reconhecer a necessidade de proteções específicas destinadas às mulheres. É no final da década de 1970 que começa a emergir no Direito Internacional dos Direitos Humanos o reconhecimento da questão de gênero como uma questão que deve retornar ao âmbito da justiça. O reconhecimento dos direitos humanos das mulheres fortaleceu o debate acerca dos direitos sexuais e da formação de subjetividades voltadas ao reconhecimento da dignidade sexual das mulheres.

A formação das subjetividades tem sido moldada por padrões agressivos, que formam um modelo de sexualidade também agressiva. Neste sentido, a sexualidade do homem deve ser sempre agressiva, dominadora, exploradora, enquanto que a da mulher deveria ser uma sexualidade submissa, destinada a servir aos impulsos sexuais dos homens. O corpo da mulher seria socialmente construído como uma "necessidade biológica" do homem, o que naturaliza a violência sexual e a permanência de uma moral machista, que, se já não encontra mais abrigo no discurso jurídico, ainda se abriga nos corações e mentes de muitas pessoas.

O Código Penal Brasileiro está caminhando para ir além da moral do macho humano, que hierarquiza as mulheres de acordo os seus interesses, para proteger a dignidade sexual, como bem jurídico intimamente ligado à dignidade humana, núcleo a ser protegido por todos os direitos humanos. Neste sentido, é de grande importância para a desconstrução da moral machista, que classifica as mulheres arbitrariamente em "honestas", "virgens", "prostitutas" e "meretrizes", a alteração do Título VI do Código Penal, de 1940, para "Dos Crimes Contra a Dignidade Sexual". Tal mudança foi operada através da Lei n. 12.015/2009, fruto da luta de inúmeras mulheres brasileiras, feministas, que reconhece que sem dignidade sexual os direitos são desumanos.

\section{REFERÊNCIAS}

ANDRADE, V. R. P. de. (2004) O Sistema de Justiça Criminal da Violência Sexual contra a Mulher. Revista Brasileira de Ciências Criminais. RBCCrim 48/260. Maio-Jun./2004. In: PIOVESAN, F.; 
GARCIA, M. (Org.). Teoria Geral dos

Direitos Humanos. São Paulo: Editora

Revista dos Tribunais, 2011. (Coleção doutrinas essenciais; v. 4).

BACILA, C. R. (2015) Criminologia e

Estigmas: Um Estudo sobre os Preconceitos. 4 Ed. São Paulo: Atlas, 2015.

BECCHI, P. (2013) O Princípio da

Dignidade Humana. Aparecida: Editora

Santuário, 2013.

BIROLI, F. (2014) O Debate sobre Pornografia. In: MIGUEL, L. F.; BIROLI, F. Feminismo e Política: Uma Introdução. São Paulo: Boitempo, 2014.

BITENCOURT, C. R. (2015) Tratado de

Direito Penal: Parte Especial: Dos Crimes contra a Dignidade Sexual até os Crimes contra a Fé Pública. 9 Ed. São Paulo: Saraiva, 2015. (v. 4).

BITTAR, E. C. B. (2011) Curso de Filosofia Política. 4 ed. São Paulo: Atlas, 2011.
CAPEZ, F. (2010) Curso de Direito

Penal, Parte Especial: dos Crimes contra a Dignidade Sexual a dos Crimes contra a Administração Pública (arts. 213 a 359-H). 8 Ed. São Paulo: Saraiva, 2010. (v. 3).

CARRASCO, C; PETIT, M. (2012) Mulheres Trabalhadoras e Marxismo: Um Debate sobre a Opressão. São Paulo: Editora Instituto José Luis e Rosa Sundermann, 2012.

CARVALHO, B. (1943) Crimes contra a Religião, os Costumes e a Família: Títulos V, VI e VII do C. Penal. Rio de Janeiro: Jacinto, 1943.

COMPARATO, F. K. (2006) Ética: Direito, Moral e Religião no Mundo Moderno. 3 ed. São Paulo: Companhia das Letras, 2006.

(2010)

A

Afirmação Histórica dos Direitos

Humanos. 7 ed. São Paulo: Saraiva, 2010.

COMPARATO, F. K. (2013) Rumo à Justiça. 2 ed. São Paulo: Saraiva, 2013. 
DAVIS, Angela. Y. (2000) Women and

Capitalism: Dialectics of Oppression and Liberation. In: JAMES, J.; SHARPLEYWHITING, T. D. (Editors). The Black

Feminist Reader. Malden-Oxford:

BLACKWELL, 2000.

D'ELIA, F. S. (2012) Tutela da

Dignidade Sexual e Vulnerabilidade. 364 f., 2012. Dissertação (Mestrado em Direito das Relações Sociais). Pontifícia Universidade Católica. São Paulo, 2012.

DUPRAT, D. (2015) Igualdade de Gênero, Cidadania e Direitos Humanos. In: FERRAZ, C. V.; LEITE, G. S. (Coords.) Direito à Diversidade. São Paulo: Atlas, 2015.

GOELLNER, S. V. (2013) A Produção Cultural do Corpo. In: LOURO, G. L.; FELIPE, J; GOELLNER, S. V. (Orgs.) Corpo, Gênero e Sexualidade: Um Debate Contemporâneo na Educação. 9 Ed. Petrópolis, RJ: Vozes, 2013.

GOLDMAN, W. (2014) Mulher, Estado e Revolução: Política Familiar e Vida Social Soviéticas, 1917-1936. São Paulo: Boitempo: Iskra Edições, 2014.
GONÇALVES, T. A. (2013) Direitos Humanos das Mulheres e a Comissão Interamericana de Direitos Humanos. São Paulo: Saraiva, 2013.

GRECO, R. (2013) Código Penal: Comentado. Niterói, RJ: Impetus, 2013.

GUERRA, S. (2013) Direitos Humanos: Curso Elementar. São Paulo: Saraiva, 2013. . (2014) Direitos Humanos:

$\mathrm{Na}$ Ordem Jurídica Internacional e Reflexos na Ordem Constitucional Brasileira. 2 ed. São Paulo: Atlas, 2014.

GUSMÃO, C. de. (1921) Dos Crimes Sexuaes: Estupro, Attentado ao Pudor, Defloramento e Corrupção de Menores. Rio de Janeiro: F. Briguiet \& c., 1921.

HALL, S. (2015) A Identidade Cultural na Pós-Modernidade. 12 Ed. Rio de Janeiro: Lamparina, 2015.

HOBSBAWM, E. (1989) The Age of Empire, 1875-1914. New York: Vintage Books, 1989. 
HUNT, L. (2009) A Invenção dos

Direitos Humanos: uma História. São

Paulo: Companhia das Letras, 2009.

KARAM, M. L. (1995) Sistema Penal e

Direitos da Mulher. Revista Brasileira de Ciências Criminais. RBCCrim 9/147. Jan.Mar./1995. In: PIOVESAN, F.; GARCIA, M. (Org.). Teoria Geral dos Direitos

Humanos. São Paulo: Editora Revista dos Tribunais, 2011. (Coleção doutrinas essenciais; v. 4).

KEINERT，R. C. (2012) Os Direitos Humanos e a Consecução do Conceito de Humanidade. In: BUCCI, D.; SALA, J. B. CAMPOS, J. R. de. (Coord.) Direitos Humanos: Proteção e Promoção. São Paulo: Saraiva, 2012.

LEFF, E. (2006) Racionalidade Ambiental: a Reapropriação Social da Natureza. Rio de Janeiro: Civilização Brasileira, 2006.

LOURO, G. L. (2014) Gênero, Sexualidade e Educação: Uma Perspectiva Pós-Estruturalista. 16 Ed. Petrópolis, RJ: Vozes, 2014.
LOUW, D. J. (1998) Ubuntu: An African Assessment of the Religious Other. Twentieth World Congress of Philosophy, Boston, 1998. Disponível em: <http://www.bu.edu/wcp/Papers/Afri/ AfriLouw.htm>. Acesso em: 03/05/2014.

MARMELSTEIN, G. (2011) Curso de Direitos Fundamentais. 3 ed. São Paulo: Atlas, 2011.

MICHEL, A. (1982) O Feminismo: Uma Abordagem Histórica. Rio de Janeiro: Zahar, 1982.

MIGUEL, L. F. (2014a) O Feminismo e a Política. In: MIGUEL, L. F.; BIROLI, F. Feminismo e Política: Uma Introdução. São Paulo: Boitempo, 2014a. . (2014b) A Igualdade e a Diferença. In: MIGUEL, L. F.; BIROLI, F. Feminismo e Política: Uma Introdução. São Paulo: Boitempo, 2014b.

MIES, M. (1993a) Novas Tecnologias Reprodutivas: Implicações Sexistas e Racistas. In: MIES, M.; SHIVA, V. 


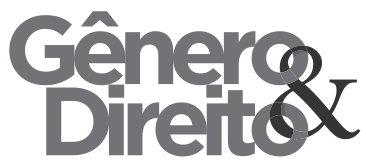

Ecofeminismo. Lisboa: Instituto Piaget, 1993a.

(1993b) O Mito do

Desenvolvimento Catching-Up. In: MIES,

M.; SHIVA, V. Ecofeminismo. Lisboa:

Instituto Piaget, 1993b.

MIES, M.; SHIVA, V. (1993) Povo ou

População: A Caminho de uma Nova Ecologia da Reprodução. In: MIES, M.; SHIVA, V. Ecofeminismo. Lisboa: Instituto Piaget, 1993.

MIGNOLO, W. (2004) Os Esplendores e as Misérias da "Ciência": Colonialidade, Geopolítica do Conhecimento e PluriVersidade Epistémica. In: SANTOS, B. de S. (Org.) Conhecimento Prudente para uma Vida Decente: um Discurso sobre as Ciências Revisitado. São Paulo: Cortez, 2004.

NORONHA, E. M. (1943) Crimes

Contra os Costumes. São Paulo: Saraiva \& Cia., 1943.

NUNES, R. (2010) O princípio Constitucional da Dignidade da Pessoa
Céco do Núcleo de Estudos e Pesquisas sobre Gênero e Direito Centro de Ciências Jurídicas - Universidade Federal da Paraíba V. 6 - No 02 - Ano 2017

Humana: Doutrina e Jurisprudência. 3 ed.

São Paulo: Saraiva, 2010.

PASSOS, E. (2009) Ética nas

Organizações. São Paulo: Atlas, 2009.

PIOVESAN, F. (2014) Temas de Direitos

Humanos. 7 ed. São Paulo: Saraiva, 2014.

PIOVESAN, F.; PIROTTA, W. R. B. (2014) A Proteção dos Direitos Reprodutivos no Direito Internacional e no Direito Interno. In: PIOVESAN, F. Temas de Direitos Humanos. 7 Ed. São Paulo: Saraiva, 2014.

PORTO-GONÇALVES, C. W. (2013) A Globalização da Natureza e a Natureza da Globalização. 5 ed. Rio de Janeiro: Civilização Brasileira, 2013.

RODRIGUES, T. de C. (2013) Tráfico Internacional de Pessoas para Exploração Sexual. São Paulo: Saraiva, 2013.

SAFFIOTI, H. (2015) Gênero Patriarcado Violência. 2 Ed. São Paulo: Expressão Popular: Fundação Perseu Abramo, 2015. 


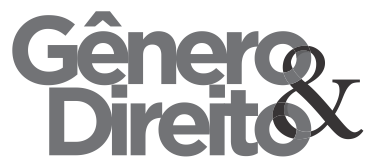

SANTOS, B. de S. (2010) A Gramática

do Tempo: para uma Nova Cultura

Política. 3 ed. São Paulo: Cortez, 2010.

SHIVA, V. (1993) O Empobrecimento

do Ambiente: As Mulheres e as

Crianças para o Fim. In: MIES, M.;

SHIVA, V. Ecofeminismo. Lisboa:

Instituto Piaget, 1993.

SOARES, R. M. F. (2010) O Princípio

Constitucional da Dignidade da Pessoa

Humana: em Busca do Direito Justo. São

Paulo: Saraiva, 2010.

TRINDADE, J. D. de L. (2011) História

Social dos Direitos Humanos. São Paulo:

Peirópolis, 2011.

WALLERSTEIN, I. (2001) Capitalismo

Histórico e Civilização Capitalista. Rio

de Janeiro: Contraponto, 2001.

ZAPATER, M. C. (2015) Esse Corpo tem

Dono? O Direito das Mulheres à

Autonomia sobre o Próprio Corpo. In:

FERRAZ, C. V.; LEITE, G. S. (Coord.)

Direito à Diversidade. São Paulo: Atlas, 2015. 